\title{
Ethical implications of a co-benefits rationale within climate change mitigation strategy
}

\section{Rita Vasconcellos Oliveira* \& May Thorseth}

Department of Philosophy and Religious Studies, NTNU Norwegian University of Science and Technology, ${ }^{*}$ corresponding author: rita.bouman@ntnu.no

DOI: http://dx.doi.org/10.5324/eip.v10i2.1942

(cc) BY 1 This is an open access article distributed under the terms of the Creative Commons Attribution 4.0 International License, which permits unrestricted use, distribution, and reproduction in any medium, provided the original author and source are credited.

The climate change mitigation effort is being translated into several actions and discourses that make collateral benefits and their rationale increasingly relevant for sustainability, in such a way that they are now a constant part of the political agenda. Taking a broader and consensual perspective, co-benefits are considered here to be emerging advantages of implementing measures to lower greenhouse gases.

Starting with the analysis of policy documents referring to two European urban transportation strategies, the emergent co-benefits are problematized and discussed to better understand their moral aspect. Further ethical reflection is conducted after an analysis of some unintended consequences of the co-benefits rationale arising from the examples. The discussion focuses primarily on the challenges of an integrative moral justification for co-benefits and also for their role in the climate change mitigation effort. We also discuss the limitations of the current normative models that frame a co-benefits rationale, both from a moral viewpoint and in relation to the overall climate change mitigation strategy.

In this article, we propose the concepts of well-being and freedom, as portrayed by the Capability Approach, as possible guiding notions for the moral and social evaluation of goodness of these emergent benefits as well as their rationale. Additionally, some preliminary conclusions are drawn regarding the potential of the presented concepts to support climate change mitigation action. Finally, we outline a scenario where the Capability Approach is the moral guideline for a co-benefits rationale and illustrates its potential in terms of enhancing climate change mitigation strategy.

Keywords: Co-benefits, Climate Change, Capabilities Approach, Freedom, Well-being

\section{Introduction}

Climate change mitigation refers generally to actions targeting the reduction and/or prevention of anthropogenic greenhouse gas (GHG) emissions. Analyses focused on how to accomplish this goal are directed at human activities that are responsible for global warming effects and at actions that may alleviate changes in the global climate pattern. Scientific studies show that to reduce human impacts on the global climate, the use of new and requalified technologies is needed, along with 
a considerable increase in the use of renewable energy sources (IPCC 2013). Moreover, incremental energy and resource efficiencies, in addition to changes in management and behaviour patterns, are also relevant contributors to mitigation efforts.

The implementation of climate change mitigation (CCM) projects through the years has provided more information beyond pre-existing theoretical knowledge, adding to our topics for study and reflection. The additional beneficial consequences arising from the application of certain options to decrease GHG, generally known as co-benefits, constitute one of these topics. A co-benefits approach is a broad concept that, in the case of this paper, refers to 'the emerging advantages of the implementation of measures regarding the lowering of GHG' (Vasconcellos Oliveira, Thorseth, \& Brattebø 2016). According to Selvakkumaran \& Limmeechokchai (2013), co-benefits are mutually beneficial interactions, in terms of energy conservation and pollution reduction, that stem from the decrease of GHG emissions. They also include the reduction of resource depletion (Jackson and others 2005) and of emissions to air, water and soil as a result of changes in agricultural procedures (Follet \& Reed 2010).

Due to the nature of the environmental problem, there are multiple areas for CCM action. Many contexts for CCM plans and actions exist, but urban settings have been and still are privileged scenarios of green policies and technologies. The reasons for this are multidimensional and complex (C40Cities 2012; UNHabitat 2012). Nevertheless, it is possible to identify a particular sort of governance as one of the important aspects (Corfee-Morlot and others 2009). A special combination of socio-economic and political aspects favours the implementation of what we might consider bold measures in CCM strategy (McEvoy, Lindley, \& Handley 2006; Tanner, Mitchell, Polack, \& Guenther 2009). These factors make the analysis of this phenomenon in this particular context especially interesting.

Though scientists (Creutzig \& He 2009; Harlan \& Ruddell 2011; Jack \& Kinney 2010) and policymakers (IPCC 2007a) have engaged extensively in the analysis of co-benefits and their rationale, there is still room, and above all a need, for philosophers to address such matters. The moral implications and ethical reflection on co-benefits issues have not yet been analysed under a philosophical lens. Cobenefits and their rationale have been addressed mostly in terms of quantification, especially through models (Singh, Stromman, \& Hertwich 2012) and cost-benefit analysis (Jakob 2006), and via assessment of particular initiatives (Aunan, Fang, Vennemo, Oye, \& Seip 2004; Changhong, Bingyan, Qingyan, Green, \& Streets 2006). The discussion around co-benefits phenomena to date has been centred on demonstrating that the additional advantages of implementing particular CCM strategies can surpass, or at least decrease the investment in, mitigation actions (Ganten, Haines, \& Souhami 2010). Nevertheless, other questions on this matter have yet to be considered, such as: How can one morally justify the outcomes of technological options, recommendations and political actions that impact the lives of so many people, and especially of underprivileged groups? How should one deal with value conflicts of CCM strategies that have co-benefits? What is the decisionmaking process when there are trade-offs between co-benefits?

The goal of this paper, through consideration of these questions, is to contribute to further reflection on moral consequences and dilemmas that arise from climate mitigation actions, in cases where the co-benefits rationale exerts a clear influence. 
By putting forward moral arguments and using ethical reasoning in relation to a specific context (urban) and with a few examples, we intend to enrich the global discussion on the consequences of climate change strategies. By adding arguments of a moral nature, we hope that more agents with environmental responsibilities will become aware of the ethical implications of their recommendations and options.

More specifically, the aims of this article are (1) to problematize the moral aspect of co-benefits, (2) to give an overview of different arguments that sustain cobenefits as moral object, (3) to reflect about consequences and dilemmas arising from a co-benefits approach and its rationale, (4) to put forward new arguments for the moral justification of this phenomenon within the CCM debate, (5) to draw some conclusions with respect to the strengths and limitations of this approach as a moral promoter of CCM action and (6) to show the potential of the Capability Approach when applied to a co-benefits rationale to enhance CCM strategy.

The paper is organized into three parts. The starting point of our analysis is a comparison between two iconic political initiatives on urban transportation undertaken in Europe. Since these strategies were highly influenced by the cobenefits rationale, we reflect on the objectives and values behind these actions. The concept of co-benefits is then defined to stress the moral dimension of this term. This part deals more closely with the moral angle of a co-benefits rationale that is subjacent to both aforementioned initiatives. The second part also includes a discussion on how to morally justify a co-benefits rationale within the CCM debate, beyond the traditional argumentation presented in literature. A co-benefits rationale is problematized around the concepts of well-being and freedom, and finally some conclusions are drawn about co-benefits rationale as a strategy to instigate climate change mitigation actions.

\section{Climate change mitigation strategies in an urban context}

More than half the world's population presently lives in cities (UN 2014), and by 2050, the urban population is predicted to exceed 6.4 billion (WHO 2010). Urban settlements are responsible for $67-76 \%$ of energy use and $71-76 \%$ of energy-related greenhouse gas emissions (Christ 2014), which means that cities are key players in mitigation strategies.

Many cities are presently trying to break out of the vicious cycle of energy- and carbon-intensive development (C40Cities 2015b), which results in higher energy costs and carbon emissions, as well as traffic congestion, air pollution, poor public health and a range of other negative impacts (Kalkstein 1993).

Despite the aforementioned problems, cities are growing every year. The reasons for urban growth are the facilitated access to people, goods, services and information. The degree of this access efficiency dictates the level of development, especially economic development (Combes, Duranton, Gobillon, Puga, \& Roux 2012). The increase in agglomeration allows high levels of productivity and the possibility of successful economies of scale and improved networking (Krugman 1993). This type of reality is only possible if the urban transportation system guarantees the fluxes of people, goods and information (Vuchic 1999).

Since the dawn of urban areas, transportation has been vital to the flourishing of any city, and this dependence is now stronger than ever. According to van Van Audenhove, Korniichuk, Dauby, and Pourbaix (2014), urban travel currently 
constitutes more than 60 per cent of all kilometres travelled globally and, as a result, urban transport is presently the largest single source of global transport-related carbon emissions and the largest local source of urban air pollution.

Urban kilometres travelled will increase threefold by 2050 (Van Audenhove and others 2014) due to urban expansion. Such unprecedented change will bring with it enormous risks associated with locking in energy-intense patterns of accessibility and urban form for decades to come (Ang 2013).

In this context, several urban mobility strategic plans are being developed at international ${ }^{1}$, national ${ }^{2}$ and regional $^{3}$ levels. All the initiatives share the overarching goal of reducing GHG emissions, but the measures being implemented are quite different.

At the start of the C40 Cities initiative, only a few European cities were involved. Now, more cities overall, including non-European ones, are participating. In the case of this paper, we will analyse two structurally different CCM actions in the urban European context.

\section{Invest in Public or Private Benefit: Two Dissimilar GHG Mitigation Strategies}

\section{City of Hasselt: 'Free Public Transportation' initiative}

One of the most radical approaches to 'greener' urban mobility took place in the city of Hasselt in Belgium. Hasselt Samen Anders Mobiel was the name of the programme designed to take ' $[. .$. . measures that will add years to our life and add life to our years's. It was an ambitious programme that covered several aspects of the city's mobility and became famous for its 'Free Public Transportation' initiative. The intention was 'to convince its population and visitors, by means of targeted marketing campaigns and an ongoing dialogue, that to travel in an eco-friendly way is better and more convenient than by car' (Lambrechts 2001:1).

The reasons to set up such an initiative were that 'Hasselt is the capital, commercial core and education centre of the province of Limburg in the eastern part of the Belgian region of Flanders. [...] Until the early 1990s, the city's public transport system was quite underdeveloped and car density was the highest in Flanders at 467 cars per 1000 inhabitants' (Brand 2008: 183).

The initiative consisted in having unrestricted public transportation because 'the city council pays for each ticket that a passenger would normally buy' (Lambrechts 2001: 14).

This approach was considered revolutionary, and similar initiatives were implemented in other cities such as Tallinn (Galey 2014) and Brussels (De Witte and others 2006). Nevertheless, in 2013 the Hasselt initiative was terminated, apparently due to the excessive and continuous rise of costs (Canters 2014).

It is relevant to mention that this was not the first instance of public investment in the improvement of urban public transportation (Dave 2014; Flyvbjerg, Skamris Holm, \& Buhl 2005). However, never before had a programme existed that made the use of public transportation free of charge for all city residents and visitors. Another relevant aspect of this initiative was the primary focus on general benefits that went above and beyond GHG mitigation. The main reasons for this programme ${ }^{5}$ were, among others, traffic safety, parking policy and increasing alternative solutions to car mobility (bikes and public transportation). These 
particularities made this initiative quite unique and a model for urban mobility planning.

\section{Norwegian cities: The boost in usage of private electric vehicles}

Norwegian cities have adopted far different plans than Hasselt did in order to achieve Norway's ambitious sustainability targets. In the case of the capital Oslo, the objectives are to reduce its greenhouse gas emissions by 50 per cent by 2030 as compared to 1991, and by 2050 to be climate neutral (Pas 2014).

In 2008, it was decided to start significantly reducing $\mathrm{CO}_{2}$ emissions, and since weather conditions during the winter months were not favourable for cycling, Oslo decided to promote electric vehicle (EV) usage. The Agency for Urban Environment and the EV community developed a plan to establish a large-scale EV charging point installation. It is important to make clear that 'Oslo's mobility strategy is found in its wider "Urban Ecology Programme 2011-2026" plan, which focuses on reducing noise levels, air pollution and greenhouse gases' (Pas 2014) ${ }^{6}$. It is relevant to understand that 'the city believes that the social benefits, such as reductions in harmful emissions, outweigh the costs of expanding the existing charging infrastructure and the transition to an electric vehicle fleet' (Pas 2014: 1).

In a similar move, the city of Stavanger has implemented the necessary infrastructure for private electric cars. The city has taken part in the EU project ELCIDIS - in order to implement an electric vehicle city distribution system which has involved a review, of urban-freight in Stavanger and a replacement of goods vehicles with electrically powered vehicles' (Eltis 2008).

In some cities such as Trondheim, EVs were also promoted as public transportation through a joint collaboration between taxi operators, utility companies and the municipality (EV Norway 2012).

In the case of the Norwegian commitment to increase the number of EVs on their roads, it is important to note that the public investment promotes both the acquisition of private property (cars) and the usage of these vehicles (EV charging points). The programme objectives extend far beyond decreasing greenhouse gases and include other beneficial outcomes such as pollution reduction that have become increasingly more important (Holtsmark 2012).

\section{Different paths with similar goals}

From the examination of these examples it is possible to draw some preliminary conclusions regarding the fundamental reasons for and objectives of such initiatives. Both examples included a goal directly related to the decrease of urban GHG emissions, and the initiatives' specific targets were in accordance with a more global policy framework, which was adapted from national guidelines to regional contexts. Moreover, in both cases public money was invested through governmental or public institutions that are under public scrutiny.

The programmes in both cities were tailored to abide by national policies, and the national policies are illustrative of the principles of international regulation on CC.

Another shared and very significant aspect of these initiatives was the existence of explicit aims in addition to the lowering of GHG. The overarching programmes and the initiatives both focused mainly on outcomes such as pollution mitigation or traffic reduction. In other words, the additional benefits, and not the mitigation of 
$\mathrm{CC}$, were the main reasons to implement the initiatives presented in the policy documents.

In the case of the Belgian city, the sustaining arguments centred on improving citizen circulation.

'The Hasselt mobility plan has 11 main objectives aimed at achieving sustainable mobility: 1 . Increase traffic safety; 2 . Directional parking policy [...] 1. To create a car-free city centre for pedestrians; 2 . To encourage the use of public transport for city tours from different areas within the region [...]' (Lambrechts 2001: 6-8).

The Norwegian Ministry of Transport and Communications developed Norway's favourable policy on EVs, which to some extent included environmental arguments (Hannisdahl, Malvik, \& Wensaas 2013).

'This combined incentive saves BEV (ongoing battery electric vehicles) commuters' money and significant amounts of time, while reducing noise and local pollution to the benefit of the public at large. (Hannisdahl and others 2013: 3).

In both examples, CCM was secondary in relation to other gains, which is thought provoking as a justification argument for public investment. This apparent inversion in level of importance adds a relevant point for reflection about the possibility of co-benefits overshadowing CCM in their rationale. Furthermore, the question arises whether the policymakers thought that CCM on its own would not be a sufficient argument for public investment.

\section{The hidden [co-] benefits and their moral dimension}

\section{Pragmatic reasons}

In the course of rationalizing and applying CCM strategies, some scholars uncovered additional positive effects that go hand-in-hand with reducing emissions of $\mathrm{CO}_{2}$ and other greenhouse gases. The urban transportation cases previously analysed in this paper are two examples of situations where further benefits emerged.

In the field of environmental sciences, different institutions and organisations have different understandings, definitions and interpretations of these additional advantages, or co-benefits. According to the Organisation for Economic Cooperation and Development (OECD 2014), 'for GHG mitigation policies, cobenefits can best be defined as effects that are additional to direct reductions of GHG and impacts of climate change and have estimated to be large, relative to the costs of mitigation (e.g. anywhere from $30 \%$ to over $100 \%$ of abatement costs)'. Additionally, they are '(monetised) effects that are taken into consideration as an explicit (or intentional) part of the development of GHG mitigation policies' (Jochem \& Madlener 2003: 6). The Intergovernmental Panel on Climate Change (IPCC 2007b: 22) considers them to be 'benefits of policies that are implemented for various reasons at the same time-including climate change mitigationacknowledging that most policies designed to address greenhouse gas mitigation also have other, often at least equally important rationales (e.g. related to objectives of development, sustainability, and equity)'. 
From a more general perspective, and in this paper, co-benefits are defined as mutual beneficial interactions that arise from decreasing anthropogenic GHG emissions, or in other words, co-benefits are considered to be emerging positive advantages of CCM action. For example, in the area of energy conservation, pollution reduction-especially gaseous pollution (West and others 2013) - is considered a co-benefit.

More recently, the concept seems to anchor further perspectives such as climate co-benefits, climate and air co-impacts (Nemet, Holloway, \& Meier 2010). This multiple understanding of co-benefits extends itself to the diversity of methods and tools for assessing co-benefits (K. R. Smith \& Haigler 2008).

It is relevant to mention what is known as development co-benefits in a regional context, which are improvements in a local setting due to the implementation of climate change policies. Examples of those benefits are improved air quality or cleaner technologies that will create better jobs in a specific region (Miyatsuka \& Zusman 2010).

Climate co-benefits also include global climate change benefits coming from the implementation of plans or sectorial policies and actions. This notion has evolved from the idea that developing countries would focus on the development of their economies before having environmental concerns (Miyatsuka \& Zusman 2010).

The following table describes some of the ideas behind the use of the term 'cobenefit' in a climate change mitigation context:

\begin{tabular}{|c|c|c|}
\hline $\begin{array}{l}\text { Impact } \\
\text { level }\end{array}$ & $\begin{array}{l}\text { Category of co- } \\
\text { benefit }\end{array}$ & Description \\
\hline Global & $\begin{array}{l}\text { GHG Emissions } \\
\text { reduction }\end{array}$ & $\begin{array}{l}\text { GHG emissions reduced mainly through cutting fossil } \\
\text { fuel consumption and improving energy efficiency }\end{array}$ \\
\hline \multirow{6}{*}{ 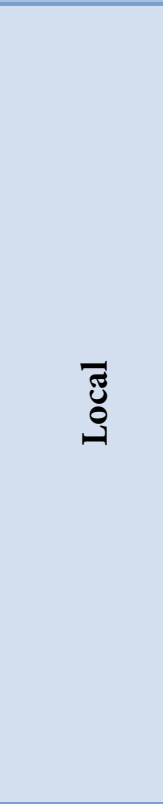 } & $\begin{array}{l}\text { Air quality } \\
\text { improvement }\end{array}$ & Reduction of pollutants, such as $\mathrm{SO} 2, \mathrm{NOx}, \mathrm{PM}, \mathrm{CO}$. \\
\hline & Waste management & $\begin{array}{l}\text { Reduced use of primary materials; reduction of } \\
\text { hazardous waste, waste materials; and reduced waste } \\
\text { disposal costs. }\end{array}$ \\
\hline & $\begin{array}{l}\text { Water quality } \\
\text { improvement }\end{array}$ & $\begin{array}{l}\text { Reduction of pollutants in water. GHG emissions } \\
\text { (e.g. } \mathrm{CO} 2, \mathrm{CH} 4 \text { ) are also reduced in the process of } \\
\text { water quality improvement. }\end{array}$ \\
\hline & Production & $\begin{array}{l}\text { Improved product quality or purity; reduced process } \\
\text { cycle times; increased production reliability; } \\
\text { increased customer satisfaction. }\end{array}$ \\
\hline & Health & $\begin{array}{l}\text { Reduced medical/hospital visits, reduced lost working } \\
\text { days, reduced acute and chronic respiratory } \\
\text { symptoms, reduced asthma attacks, increased life } \\
\text { expectancy. }\end{array}$ \\
\hline & Economic & $\begin{array}{l}\text { Increase in local GDP and employment rate. } \\
\text { Improved welfare. }\end{array}$ \\
\hline Other & & $\begin{array}{l}\text { Improving the working environment (e.g. improved } \\
\text { lighting, temperature control and air quality; reduced } \\
\text { noise levels; reduced need for personal protective } \\
\text { equipment; increased worker safety.) }\end{array}$ \\
\hline
\end{tabular}

Table 1: General aspects of the co-benefit term in sustainable development discourse. Adapted and expanded from Jiang and others (2013). 
Some of these additional benefits are found at a regional level and are thus more visible and relevant for communities, such as more green jobs in clean energy production (Yi 2013), while others have a global effect, such as the improvement of air quality (West and others 2013).

\section{The moral side to co-benefits}

Taking a closer look at the initiatives described, it is possible to uncover several additional advantageous consequences to lowering GHG. Both initiatives were designed to create specific co-benefits (e.g. decreased traffic noise, improved mobility), which were cited as being the major objectives. In other words, they were designed under a co-benefits rationale and not solely for the purpose of fighting climate change. The political option of presenting only CCM as the orienting idea and justifying argument would also be possible, since the European Union has legislation and climate targets (Pew Center 2009) that would suffice for the development and validation of both initiatives. However, this 'CCM rationale' was not chosen by these policymakers, who preferred a co-benefits approach as the guideline and as the means for public validation.

In both initiatives, co-benefits were publicly presented as valid reasons for implementing these GHG-lowering emissions strategies. This co-benefits rationale is also found in other CCM general strategies and initiatives (Nemet, Holloway, \& Meier 2010).

These examples create an additional opportunity for further reflection about the adequacy and suitability of a co-benefits rationale.

The general literature on co-benefits ${ }^{7}$ consistently states facts and numbers that have created a shared belief, especially present in policy documents, that co-benefits are good and desirable (Aunan, Fang, Vennemo, Oye, \& Seip 2004; Creutzig \& He 2009). The article 'Counting good: quantifying the co-benefits of improved efficiency in buildings' from Ürge-Vorsatz, Novikova, \& Sharmina (2009) is a striking example of how the environmental sciences view co-benefits and how they justify their rationale.

Besides the scientific evidence for a potential good, the idea of co-benefits itself holds a latent notion of some kind of rightness. The concept of 'benefit' carries a positive emphasis that can be analysed under a normative perspective. Moreover, it also points to an evaluative setting, meaning that an ethical side must be accounted for. In addition to these factors, there is a societal shared belief about the emergent outcomes of CCM that deserves to be philosophically analysed under a moral scope.

Through the examples mentioned above, we shall consider the possibility of moral justification for co-benefits and their rationale.

\section{Hasselt's and Oslo's urban transportation initiatives: the influence of a co-benefits rationale}

Both CCM literature and related policy documents (WHO 2012; Ürge-Vorsatz and others 2009) enable us to establish that a co-benefits rationale encompasses two different notions. Firstly, co-benefits are used to support acceptance of and compliance with policies and regulations aiming at CCM, in what could be called, on the one hand, a rhetorical-persuasive use. At the same time, there is another dimension that can be called an ethico-economic use. Here, co-benefits are part of an attempt to weigh and assess the justifiability of mitigation policies and 
regulations, i.e. to answer the question: 'Are CCM policies worth the sacrifices and costs they require?'.

The cases of the Belgian 'Free Public Transportation' initiative and the Norwegian boost of private electric vehicle usage policies are strong examples of these notions.

The Hasselt initiative, created just before the new millennium, was driven by specific ideas about urban mobility development within a context of sustainable development. As Lambrechts (2001: 29) states, 'all the measures [...] should make Hasselt a city with a sustainable quality of life. A city that takes future generations into consideration'.

On the grounds of the rhetorical-persuasive use of a co-benefits rationale, the text below alludes to a possible deontological framework that would confer additional normative strength to the argumentation in favour of the initiative.

'By making public transport free of charge it became possible to guarantee the right to mobility for all residents. The threshold was laid so low in fact that each and everyone was able to enjoy their right to mobility' (Lambrechts 2001: 13).

Nevertheless, in order for such arguments to have true deontological weight (in the sense of an ethico-economic use), specific requirements need to be met. One possibility is the conformity to established moral rules based on duties and obligations that can, in some cases, be translated into rights. In our specific cases, and in the analysed documents, there is a line of argumentation that tries to justify the subsidization of public transportation and of electric vehicles based on some type of moral obligation of the authorities to guarantee a supposed right.

Though it might be appealing to use the term right as a means of political and social justification, first one must be theoretically sure that the concept and the necessary deontological matrix can be applied to both the specific (e.g. mobility, sustainable community) and the general co-benefits.

In the case of Hasselt's initiative, mobility is presented as an established social right, granted to all citizens, regardless of their background or economic condition. In general, countries recognize the right of their citizens to travel and move within their countries and abroad-with varying restrictions - in their constitutions or general laws.

Nevertheless, considering Hasselt's example, the word right relates here to further entitlements than just the possibility of freedom of movement sensu stricto ${ }^{8}$, which is the meaning present in the Human Rights Declaration and 'deontological' literature (IOM \& UNDESA 2012).

In our example, mobility refers to a good or adequate way for people to move. Confirming this hypothesis, Lambrechts (2001: 2) describes that 'we have seen a shift from mobility to sustainable mobility. [...] Sustainable mobility policy stands for the development of a form of mobility that takes into account the needs of the current generation without endangering the mobility needs of the future generation'.

This perspective of extended mobility is shared by other cities (Díaz \& Paez n.d.) and governments (Cresswell 2006), especially when it comes to attaining sustainable mobility (Van Neste \& Sénécal 2015).

Although the moral justification of mobility sensu stricto, from a deontological perspective $^{9}$, may not cause an uproar, the response is different when a more 
integrative definition ${ }^{10}$ is examined. A concept of mobility that integrates sustainable considerations brings more controversy to the table. For example, a right to sustainable mobility includes some consideration of future generations, which is still at the core of many fiery debates (Boyle 2006; de Sousa Santos 1999).

Other sources of questions and obstacles to a clear validation of the right to sustainable mobility stem from this possible right: Should the right to sustainable mobility be considered under the umbrella of environmental rights? Or simply as an extension of human additive goods?

A possible 'right to mobility' has a strict relationship to a narrower anthropocentric perspective, where the achievement of a condition will allow the agent to increase his or her possibilities of self-fulfilment and/or his or her capacities for particular actions. On the other hand, a right to a 'sustainable mobility' has to measure up to at least certain environmental aspects that are completely missing in the previous right. Even without regarding what sustainability might mean in such a context, it always includes natural systems, even if in a subordinate relationship to the human one. Consequently, from a moral viewpoint, considerations on what might constitute a 'healthy and flourishing environment' or 'general satisfactory environment favourable to [people's] development' (Boyle 2006: 33) must be weighed against the obligation to promote mobility. This possible conflict is exacerbated in the Hasselt example, since the aim of that policy was to put people at the centre of the considerations. The need to consider other aspects, such as the environment, makes the trade-offs even more difficult.

However, in the general context of this particular co-benefit, the inclusion of the environment appears to be mandatory because it is part of a greater strategy to address climate change, and yet policy and societal discourse do not fully recognise this assertion.

Comparable questions and points of dispute arise when we read the policy texts referring to Oslo's initiative to boost private electric vehicle usage.

'The city (Oslo), which currently holds the record for the European continent's smallest per capita carbon footprint, aims to be a sustainable urban community where everyone has a right to clean air, clean water and access to attractive outdoor recreation areas' (Røsland 2013: 2).

The words of Stian Røsland, mayor of Norway's capital, clearly express a normative aspect of collateral benefits coming from Oslo's sustainability plan, which includes the electric car initiative. In the same vein as the Belgian politicians in Hasselt, Røsland emphasises the importance of climate change actions to promote citizens' rights. However, in this case the considered right is not directly connected to mobility but to good natural resource quality.

In the case of water, the right to this resource has already been recognised both morally and legally (Gleick 1998; OHCHR, UNHabitat, \& WHO 2010; Salman \& McInerney-Lankford 2004). As for air, there is no international legal statement about a specific human right to it, but the quest to assure access to clean air for everyone, in the sense of air free of pollutants, has been acknowledged internationally via the UN (CCAC 2015).

The possible right to a sustainable community has not yet been clearly stated as a legal or moral right. However, several institutions are lobbying to 'build sustainable communities by assisting people to assert their right to local self-government and the rights of nature' (CELDF n.d.: 1). 
Despite the effort to establish a deontological normative-oriented argumentation, a second look at the explanatory texts of both initiatives unveils another, probably even more relevant, moral guideline. In both cases, the outcomes of the CCM initiatives (sustainable mobility, clean air and water and attractive outdoor recreation areas) are the real 'moral compasses' for the evaluation and consequent justification of the strategies. Throughout co-benefits literature (Vasconcellos Oliveira and others 2016) and also in CCM strategizing (Dietz \& Asheim 2012), the consequentialist moral frame has so far predominated, and these particular examples seem to incorporate their influences.

All documents emphasise the positive outcomes but not the principle of acting to mitigate GHG emissions ${ }^{11}$. Interestingly, the desired consequences, which are portrayed as rights in both documents, are themselves good consequences that should be extended due to their perceived relevance. The use of public transportation (Hasselt) or electric private vehicles (Oslo) are means of guaranteeing that more people (i.e. 'all citizens') have access to more good (e.g. 'mobility, clean air and water'). In the documents, the collective perspective has a special prominence, as in any utilitarian reasoning, since it is the action of more citizens that creates the existence of the benefit and the possible extension of it.

The analysis of both Hasselt and Oslo urban transportation initiatives shows a 'hybrid' use of moral arguments and reasoning. In these two cases, the co-benefits rationale, in terms of ethico-economic use, is infused by a utilitarian approach, but at the same time, it also integrates deontological jargon and some deontological influences. The use of a 'rights terminology' aims at reinforcing moral power in an attempt to rhetorically legitimize the strategies. The use of both moral traditions likewise expresses the realization by the policymakers of the difficulty, and the necessity, of finding a coherent and inclusive moral framework for co-benefits.

In summary, the justification of co-benefits and their rationale through a rights (moral and legal) perspective, both in general cases and in particular cases (e.g. water, air), is achievable without major effort. Society (legal rights) and ethicists (moral rights) have already established a set of arguments and a type of reasoning in favour of recognising these co-benefits as rights, and these reasons are not being challenged or contested.

However, the overall strength of the argumentation would not be enough to establish other types of co-benefits (e.g. sustainable community and mobility) as moral and/or legal rights, despite the existence of some potentially favourable arguments, such as welfare. In addition, the lack of a solid basis favouring the recognition of these co-benefits as rights opens the door to counter the overall justification (e.g. hierarchy of importance within rights), if a deontological approach were to shape the rationale.

When collateral benefits cannot be regarded as basic, inalienable rights or as relevant for human dignity, but instead provide some degree of good or well-being, or are interests ${ }^{12}$, they are worth being morally justified. As mentioned before, not all co-benefits have the characteristics to be considered under the dimensions of moral and/or legal rights (Rea 1986). However, co-benefits can still be considered claims (e.g. access to attractive outdoor recreation areas) or responsibilities (e.g. mobility that takes into account the needs of the current generation). When this is the case, they-and by extension the argumentation around them-deserve to be 
morally analysed, in order to understand of the possibility of a plausible justification.

Another possibility for justification would be to address co-benefits from a perspective of utilitarian goods, which is in line with the rest of climate change policy.

So far, utilitarianism has been the best-known form of consequentialism and has deeply influenced not only ethical thought but also political and economic theories. More recently, utilitarianism has entered the environmental arena.

There are several variants of utilitarianism; however, they all focus on the 'quality of the consequences'. The ruling principles are the following:

'If and only if the consequences of a particular act would be worse than those of some alternative, then it would be wrong for that act to be performed. [...] If and only if the consequences of everyone's doing a certain sort of thing would be worse than those of some alternative, then it would be wrong for anyone to do such a thing.' (Feinberg 1967: 369)

Defined more broadly and simply, utilitarianism holds that each individual is morally required to act in such a way as to produce the most good. The classical utilitarians (e.g. Bentham, Mill or Sidgwick) regard good in terms of pleasure, pain or happiness. This perspective evolved and became more pluralist, for example including other values such as beauty (Crisp 2013), potential Pareto improvements, wealth or even GNP (Sagoff 1986).

More recently, in response to criticism from deontological ethicists, the objective of a good action has become more nuanced. For example, the utilitarian author Jamieson considers the objective of utilitarian action as the creation of the best outcomes, here perceived as well-being (O'Brien, Clair, \& Kristoffersen 2010). It is important to bear in mind that, independently of the utilitarianism version, one's own well-being has the same value as others' well-being.

Furthermore, there is an obligation towards maximizing the overall good. In other words, maximizing the overall net benefit, often referred to as aggregate wellbeing or welfare, is the goal. Utilitarians 'calculate' aggregated welfare by assessing the benefit or harm to each individual, and then adding all the benefits and harms together to reach an aggregate sum. Though this accounting might seem straightforward, there is considerable dispute among theorists about how best to account for welfare (Hooker 2015).

In general, utilitarianism is quite appealing and intuitive, especially under Jamieson's influence (Jamieson's dictum). But there are relevant limitations to this line of justification, both in general (Jamieson 2012; O'Brien and others 2010: 1467 ), and in the case of the environment (Jamieson 2007).

The reason for not justifying co-benefits with utilitarian arguments is the difficulty in maximizing these outcomes while maintaining the primary goal of CCM. This shortcoming exists whether future generations' needs are included or not.

In our case, the facilitated purchase of electrical vehicles, designed to increase access to urban outdoor recreation areas, might actually jeopardize recreational quality and attractiveness. In addition, it is challenging to account for urban mobility needs of future generations since they will depend heavily on environmental (e.g. resource availability for battery production) and technological factors that are not under the cities' sphere of influence. 
In general, and in the case of public transportation in Hasselt, the justification of co-benefits from a utilitarian perspective might serve the majority (general population) well, but it does not satisfy the interests of minority groups, since the utilitarian principle of increased good for more people subordinates the good for a lesser number of individuals. In the next section, we propose further arguments to show the limitations of this accounting approach. In addition, we will present and discuss other characteristics and impacts of co-benefits that need to be accounted for, if we hope to find a coherent way to understand the moral implications of their rationale.

\section{Some unexpected moral effects of co-benefits}

Specialised literature seems to be rather unanimous in regarding co-benefits of CCM as a powerful argument to engage society in a common effort to mitigate climate change (Bollen, Brink, Eerens, \& Manders 2009; Ganten and others 2010; Jack \& Kinney 2010; Smith 2013). We argue here that, at least to a certain extent, some CCM strategies can, because of their emergent (co-)benefits, be morally justifiable under the reasoning of different moral traditions. This positive effect can also help us understand why a co-benefits rationale is perceived by society as being intrinsically good.

Nevertheless, this scenario hides certain perils when it comes to the accounting of its raison-d'être. As mentioned in the Hasselt initiative, co-benefits can, and sometimes do, overshadow the primary reason for putting them into practice, which is to lower GHG emissions (Ganten and others 2010; Puppim de Oliveira 2013).

This reverse reasoning might not seem important at first, but when it is possible to meet the same objective by implementing different actions, the deliberation can become a hostage to considerations (e.g. social and/or political acceptance) that are neither moral nor environmental. For example, in order to decrease GHG in a regional context (Europe), it is possible to opt for reforestation (Olander, Galik, \& Kissinger 2012) or for low-carbon energy sources (Ringel 2006), but contextual factors (e.g. international policies and organizations) dictate specific actions, such as European green certificates for renewable energies.

In general, the deliberative factors are different in nature from the main purpose of decreasing GHG emissions, and they can sometimes even be opposed (e.g. public transportation versus private electric vehicles). The decision-making process regarding environmental policies, including CCM, involves various dimensions, but economic and geo-political factors are decisive, both at international and national levels (Haldén 2007; McKibbin \& Wilcoxen 2002). Environmental policies are adapted and moulded to accommodate other interests that, in many cases, carry more weight than GHG reductions in the process of implementing CCM measures.

From a purely environmental perspective, certain CCM initiatives, such as the ones related to energy efficiency, can induce the so-called rebound effect (Herring, Sorrell, \& Elliott 2009). In the case of our examples, the increased use of EVs, without a concurrent consequential replacement of combustion engine cars, increases energy expenditure. Such an increase always has a negative effect on sustainability, in general through more resources used, and in particular through GHG emissions, if the new electricity demand is satisfied with higher carbon sources than hydropower (Hawkins, Singh, Majeau-Bettez, \& Stromman 2013). If 
this scenario occurs, the right to a sustainable community (the city of Oslo's commitment) is jeopardized by an apparently greener energy option (electricity).

In the examples cited, although the policies' main focus is mitigating climate change, the intended co-benefits are of different natures (improved mobility in Hasselt and clean water and air in Oslo). As previously shown, co-benefits can be morally justifiable to a certain extent. But the actual turn of events in those cities challenges this scenario.

Free public transportation indeed changed the behaviour of Hasselt's citizens but in unexpected ways, since 'travellers transferred from cars, but cyclists also started using the free bus' (Canters, 2014: 2). This meant that for the former cyclists and for the community in general, neither the primary objective of lowering GHG nor the co-benefit of sustainable mobility were attained. Moreover, there is a large margin of uncertainty regarding the overall impact of this strategy for GHG emissions, since no studies were conducted to ascertain the number of new private vehicles on the road after free public transportation was implemented. Consequently, this raises the question of what the true co-benefit level was.

In general, co-benefits suffer from various difficulties in their accounting and quantification. Their existence and consequent positive effect are dependent on factors (e.g. time frame, scale) that are outside the control of the scientist and/or legislator (Aunan and others 2003). This creates situational conditions that are hard to foresee and to describe. Indeterminacy may threaten the argumentation for scientific, political and moral justification. In the case of the Norwegian EV use incentives in Oslo, the co-benefits of clean air and water are limited to the possible positive effects of the first 50,000 electric cars, since the incentives will stop after that target is reached.

Co-benefits may also create conditions for inequality, real or perceived. Given the fact that EVs are pricier than comparable combustion engine cars, it can be argued that this incentive benefits a group of people that are already better off. Such fact creates more social disparity, which is contrary to the core values of sustainability (Wilkinson, Pickett, \& De Vogli 2010).

From the analysis of unintended effects and factors related to co-benefits rationale, the questions that we pose now have new nuances: Are co- benefits (morally) justifiable in themselves, and also as rationale for action on climate change, even if they are difficult to access, may contribute to more inequality, and with some probability, may increase GHG too?

\section{Well-being and freedom: key concepts of co-benefits' moral justification}

In a co-benefits rationale, it is very common to depict a consequentialist mind frame that uses models and cost-benefit analyses to focus mainly on demonstrating the good (or in many cases, just the potential good) of implementing certain climate change mitigation actions (Vasconcellos Oliveira and others 2016). The same reasoning can be detected on the urban transportation initiatives in the previously mentioned examples.

Looking closely at Hasselt's free public transportation initiative, it is worth noting that this particular measure was designed to facilitate access for more people for a specific good: mobility. The same principle holds for the subsidized sales of electric vehicles in Norway. It can be argued that the co-benefits of clean air and 
water are also goods that will become available to more citizens because of a climate mitigation strategy. The reason that mobility, clean water and air can be labelled as 'goods' is because they have some kind of utility, in the sense of giving clear advantages to the people that have access to them, in contrast to people who do not.

Finding a moral tradition that offers good arguments for the ethico-economic use of co-benefits, besides the deontological one, may yield good outcomes for the justification of some co-benefits. For example, in the case of 'sustainable mobility', we can argue that co-benefits increase the level of well-being, both individually and collectively. Moreover, when the co-benefit involves resources, such as air and water, the utility becomes more visible. This line of reasoning aligns with a simplistic version of utilitarian arguments for what can be considered morally correct, and it is commonly used as a justification argument in co-benefits literature, both political (Bollen, Brink, Eerens, \& Manders 2009; IPCC 2013) and scientific (Shrestha \& Pradhan 2010; Teng \& Jotzo 2014).

Nevertheless, as Vasconcellos Oliveira and others (2016) point out, there are relevant limitations to a consequentialist approach to co-benefits, especially due to the nature of several climate change strategies and to the unexpected effects of some co-benefits.

Despite the difficulties mentioned so far in morally justifying co-benefits and their rationale, the sense of improved citizenship and personal good generated by the action of co-benefits (e.g. access to attractive outdoor recreation areas) is undeniable. It is plausible to link these effects to some kind of improved well-being, which can be related to a moral perspective: the Capability Approach.

In the case of the capability approach (CA) framework, co-benefits are not considered sources of personal utility. They would not be assessed as or compared to a means of freedom, nor as a means to achieve a just equality. In contrast to deontological and consequentialist traditions, CA offers relevant arguments for a more integrative moral justification of a co-benefits rationale because (1) it gives priority to (human) well-being and freedom, accommodating both (2) the uncertainty of co-benefit outcomes and (3) possibly some problematic trade-offs.

\section{Primacy of human well-being}

The well-being in the CA perspective is quite distinct from the widely known utilitarian notion. In the capability approach, '[the] achievement of a person can be seen as an evaluation of the "wellness" of the person's state of being' (Sen 1993: 276).

Applying Sen's perspective, it is possible to establish that if the co-benefits enable the subject's functionings ${ }^{13}$, they can be morally justified, since 'functionings are seen as central to the nature of well-being'(Sen 1993: 276). In addition, co-benefits can also be defended if they assist in expanding 'feasible alternative combinations of these functionings' (Anand, Hunter, \& Smith 2005: 12). In other words, if cobenefits extend peoples' capabilities ${ }^{14}$, then they can be justified.

Nonetheless, CA's central focus on the individual may create concerns about the possibility of a moral justification for co-benefits that occur separately, in time and space, from the agents that make the investment. This particular aspect is a very acute problem in CCM and climate change adaptation discussions, especially related to issues of justice and equity between nations (Shukla 1999) and individuals (Jamieson 2001). The current debate about the implementation of certain measures, such as carbon taxes or north-south technology diffusion, seems to be dominated by 
questions regarding who pays for and/or receives the benefits from investing in CCM strategies (Rübbelke 2011; Speck 1999).

An alternative to the erosion of the co-benefits rationale due to the issues mentioned above is to shift the moral focus from an impersonal collective to the individual, here considered to have external sources of well-being (Sen, 1985). This particular idea of integrating others' considerations, without 'externalizing' them, justifies the adoption of CCM strategies that produce co-benefits which improve others' functionings and capabilities.

The fact that CA puts the individual at the centre of moral (and social) evaluation is aligned with a general sustainability perspective (Seghezzo 2009). CA still leaves room for further developments 'without rendering it anthropocentric' (Mabsout 2015: 88) and making it possible to include co-benefits that involve non-humans (e.g. biodiversity) (Onaindia, de Manuel, Madariaga, \& Rodríguez-Loinaz 2013) in the same justification rationale.

Ballet, Bazin, Dubois, and Mahieu (2011: 1832) write that 'natural resources and the environment more generally, play a key role in shaping the structures of people's capabilities through the opportunities and constraints that they generate. In other words, they reinforce or inhibit people's ability to build real freedom for themselves, and to choose amongst various types of freedom'.

Another advantage offered by the CA evaluation system is that it combines, and extends, the consequences for the individuals (advantageous and disadvantageous), and the non-sequential features of the human dimension, such as deontological rights (Osmani 2008).

Using CA, it is possible to justify both the co-benefits arising from the initiatives previously described in this paper, and also the CCM actions that led to the cobenefits. The reason for this is that they both strive to extend the agents' capabilities and functionings. In the Belgian initiative, the guarantee of the right to mobility for all residents is in accordance with a society which promotes the intrinsic dignity of human freedom and people's ability to be subjects of their own' (Deneulin \& McGregor 2010: 514) are relevant goals.

The same line of argumentative justification also responds adequately to the different types of co-benefits that exist. The co-benefits used here as illustrations exemplify both basic (right to clean air, clean water) and complex functionings (right to sustainable mobility and access to attractive outdoor recreation areas), which determine the justification for their pursuit, and also for the strategies that make them a reality.

The unfinished and therefore open nature of the well-being concept in this framework enables the addition of new and more multifaceted factors that improve agency. In the words of Sen (1993: 274), 'the functionings relevant for well-being vary from such elementary ones as escaping morbidity and mortality, being adequately nourished, having mobility, etc., to complex ones such as being happy, achieving self-respect'.

One of the challenges to the co-benefits rationale previously mentioned was how to justify (morally, socially and even environmentally) the goodness of co-benefits and their rationale, if there is uncertainty about the real positive outcomes of certain CCM strategies. As described before, positive effects can mask unfairness (e.g. privileged access to better e-cars by a small number of well-off Norwegians) if considered from a deontological or even utilitarian perspective. 
But improvement for a few (i.e. happiness for small number of well-off Norwegians) might still be morally justifiable through the CA lens-which is vague and purposely incomplete (Basu 1987) in its description of well-being. It is possible to claim that sustainable mobility and driving EVs improve the agency of those particular individuals by creating more and better possibilities for them to live their lives.

The evolving nature of CA's well-being concept accepts more and newer capabilities and ways to achieve them. This is particularly relevant for the cobenefits rationale because not all positive outcomes are theoretically predictable, and also because newer climate change mitigation strategies are being devised and enacted every year (Biesbroek and others 2010; Birkmann, Garschagen, Kraas, \& Quang 2010; Moss and others 2010).

To maintain coherency, the co-benefits rationale must adapt to newer benefits and their characteristics but still not fail to analyse them. By integrating a CA perspective, which includes continuous evaluation of well-being and agency success, the co-benefits rationale would be in sync with the continuous and innovative nature of CCM strategies, without losing moral credibility.

The looser and non-static description of well-being in CA can also effectively account for the socio-economic and historic-cultural contingencies which a cobenefits rationale faces in particular sub-settings of the original political or geographic incidence. For example, Wittman \& Caron's (2009) study shows that the implementation of a global CCM plan (Clean Development Mechanism of Kyoto Protocol) had very different impacts, depending on the national context. Implementing a global common strategy also had unintended effects, such as an increase in social inequality in some countries. Using CA to assess the plan would be an example of what Alkire (2005) calls a 'situated evaluation'. This means that consequences and obligations (e.g. rights) would be considered to reach a decision (direct, indirect, foreseeable and unintended), within a framework of integrating human development with well-being.

\section{The importance of freedom in co-benefits trade-offs}

Both politicians and scientists face great challenges in how to deal with trade-offs when devising and establishing measures to combat anthropogenic $\mathrm{CO}_{2}$. The biggest part of the burden is knowing how to prioritize negative outcomes (e.g. valuation of environmental impact categories) ${ }^{15}$. Nevertheless, with the introduction of a co-benefits rationale in the overall climate change discourse, the burden of trade-offs now includes another dimension. By taking account of the positive effects of CCM strategies in the political agenda, reflecting on the establishment of action guidelines and priorities for 'distributing' benefits is inevitable.

In this paper, trade-offs will not be extensively dealt with since they are not a prime objective. Nonetheless, we will add some newer arguments, just within the co-benefits rationale, which might secondarily impact the ongoing discussion on matters of CCM trade-offs.

In our opinion, with the diversity of co-benefits and the settings where they arise, creating a system where guidelines for their moral evaluation are flexible and not established a priori is critical to accommodate this diversity. Because of the evolving nature of the climate change phenomenon and of the human relationship to it, any 
principles used to judge the importance and allocation of benefits must be in relation to the society that created them, and also in relation to humanity.

Sen offers a powerful tool for a more integrated path to decisions on these matters in his CA framework. He advocates for a system of social evaluation that makes space for the evolving nature of human society and for the relationship between it and climate change. The system promotes diversity and citizenship, values that are in consonance with the ones promoted by sustainability.

'Three meta-principles lie at the foundation of Sen's system of social evaluation: (1) emphasis on the need for incorporating informational diversity in structure of analysis, (2) advocacy of the notion that no moral system may be capable of yielding a complete evaluation in a world characterized by irreducible plurality of values and attributes of both individuals and of social state they inhabit, and (3) a deep commitment to democratic values' (Osmani 2008: 31).

Using the above principles may help decision-makers deal with co-benefits tradeoffs by (1) sharing the burden of decision making with the rest of the citizens, (2) achieving, or at least making an effort toward, social consensus, increasing the opportunities for (3) reflecting on climate change mitigation, and (4) reinforcing the importance of civil society through (5) democratic procedures.

The democratic traits of this process relate directly to a central concept for decision-making: freedom. It may be impossible to reach a complete and satisfying answer to all trade-offs, but an open social construct around values and expectations increases the possibility of achieving something meaningful for more people.

There is also an individual level of freedom in this process, which translates to the possibility and responsibility of being an active part of the reflection and decision-making process around co-benefits. According to Anand and others (2005: 43), the objective of policymakers should not be to make choices for people or tell them what to do, but should rather focus on 'enhancing the choice set available to everyone'.

In conclusion, several plausible arguments exist for a shared belief that cobenefits are good and that their rationale has enough moral force to impact the general CCM discourse. Such arguments resonate particularly well with the CA approach, especially if the justifying arguments revolve around well-being and freedom as discussed. Despite some possible negative effects of particular CCM strategies, co-benefits argumentation can be a good ally in the struggle for change if the rationale is built around the improved agency of the individual. A collective discussion on what CCM actions are justifiable under the umbrella of a co-benefits rationale, while protecting individual opportunity to achieve what one considers valuable, would support this struggle for change.

\section{The shape of a co-benefits rationale under $C A$}

As argued in the previous sections, a co-benefits rationale is influenced mainly by the utilitarian and deontological traditions. However, if a CA moral framework is applied to a co-benefits rationale, CA alters both the rhetorical-persuasive and ethico-economic uses of this concept.

In order to show such modification, we will use the examples of the urban transportation initiatives of Hasselt and Oslo to (1) confirm the impact of the moral 
framework in the policy outcome, (2) better distinguish between the moral influences in the co-benefits-CCM policy and (3) draw a possible scenario where a co-benefits rationale is under CA influence.

As previously mentioned, both Hasselt's and Oslo's urban transportation initiatives were influenced by ethical-moral guidelines that reflect the deontological tradition. Yet, had the initiative design and supporting documents applied this ethical tradition in a coherent way, other arguments would have been included.

Supporting statements would most likely have argued that national and local politicians could facilitate and/or make possible the right kind of mobility to address sustainability issues in all cases (e.g. public investment in free public transportation is the best way to guarantee sustainable mobility in all cities).

Policies might state reasons why they choose to treat their citizens in certain ways and/or why they permit the rights' holders to act in a particular fashion, even if some social and environmental aims would be served by doing otherwise (e.g. cycling emits less GHG and allows mobility freedom).

In other words, under the influence of a rights tradition, politicians would establish and endorse these initiatives (public transportation and EVs) because citizens could demand not only the possibility of having greener transportation options, but could also claim that the state had a responsibility to incentivize them. Policymakers would thus feel a duty to create such initiatives as responses to their 'moral obligation' towards national and/or international compromises in decreasing $\mathrm{CO}_{2}$ emissions ${ }^{16}$.

If the same politicians were to adopt a utilitarian framework, the initiatives and supporting documents would have distinct characteristics.

In the case of Hasselt's mobility programme, the free public transportation programme might maintain the same practical characteristics because more citizens would have access to improved mobility. In addition, by making it free, all economic strata would have access to the benefit.

The Norwegian strategy favouring the purchase of EVs would probably not be implemented in a utilitarian framework, since alternative ways to decrease urban GHG and foster a sustainable urban community could give everyone-not just those able to afford an EV-access to clean air, water and attractive outdoor recreation areas. The Hasselt example would be a striking alternative for this framework.

However, if both initiatives were implemented, the related policy documents would then portray much different arguments than the original ones. The quantification of benefits would likely serve both as rhetoric-persuasive and also as ethico-economic arguments to sustain the claim of increased citizen satisfaction and happiness and/or to show economic gains in those particular regions, i.e. through the use of indicators such as gross value added (GVA). For instance, reports and other official papers could mention the growing number of satisfied passengers using Hasselt's public transportation, the increase in local car trade or even the rising number of environmentally conscious Norwegians who now had the chance to buy an EV.

This kind of improvement in the overall good would be enough to justify the political and financial investments driven by the implementation of the strategies.

Supposing that CA would influence the co-benefits rationale of our examples, the shape of the initiatives would again be rather different from the frameworks 
mentioned above. Freedom and well-being would be the key guidelines for establishing any CCM programme, and a period of citizen consultation would be highly probable. This pre-event would enable people to venture their opinions or to choose from options given by the local or national authorities. This framework would create a much more bottom-up process, in which democratic procedures and citizen input would dictate the positive outcome choice.

Regarding possible argumentation to sustain the initiatives, the overall reasons in the policy documents might remain unaltered, since CA accommodates both rights (moral and legal) and an increase in good outcomes. Nevertheless, additional arguments would be added to support such claims, since CA promotes the inclusion of multiple principles (e.g. distributional concerns for the least well-off, or universalization principle) in the evaluation process. CA's plurality of informational sources and moral principles contrasts with the other traditions, especially deontology.

A co-benefits rationale with a CA slant-as distinct from abstract utilitarian maximizing principles or deontological universal principles-would include a contextualized (space and time) search for ways to achieve social justice. If the Hasselt and Oslo urban transportation initiatives had been shaped by CA, the supporting political documents would mention how the moral and political choices were made.

Of greatest relevance with respect to the influence of ethical traditions in a cobenefits rationale is that a CA approach would transform the implementation of CCM strategies into a moral 'multi-criteria' process. This process would give citizens an active voice in selecting which added benefits they consider worth having. Communities would likely repeat the selection process to continuously stay in accordance with what citizens believe to be adequate for their own situation. Again, CA reveals a significant difference from other ethical perspectives. For instance, since deontological or utilitarian moral principles are established a priori and in a single phase, it would not be necessary to morally 'revise' the value of the initiatives or their sustaining argumentation.

CA would transform a co-benefits rationale in such a way that citizens would become directly responsible for their choices, and consequently, the political rhetoric-persuasive side would carry less weight in the rationale. Instead, the focus of the rationale would be on how to better translate improved agency into action, i.e. how could co-benefits enhance those people's valuable doings and beings. In addition, and again in contrast to other moral perspectives, more stakeholders (e.g. NGOs, minority political parties, civic organizations, SMEs) would be invited to participate as a result of integrating a plurality of values and information during the deliberating process.

A democratic process of analysis and choice with regard to CCM strategies and possible favourable outcomes might also yield another positive outcome: increased population engagement. This engagement might, in the case of our examples, prevent media criticism (Oslo) and termination of the initiatives (Hasselt). The possibility to re-shape the initiatives according to citizens' moral understandings and social expectations might also create a more favourable environment for CCM. 


\section{Conclusions}

Presently, co-benefits are included in CCM strategy as positive outcomes of the social and economic effort to combat anthropogenic CO2 emissions. Besides these emergent effects from implementing particular initiatives, a complete rationale conveys the message of rightness and also serves as justification for carrying out several of these actions. A shared notion of correctness and the use of co-benefits as moral arguments in favour of particular socio-economic and political actions deserve to bear ethical scrutiny, in order to understand if there can be a moral justification for co-benefits and their rationale.

By closely analysing two European urban transportation programmes designed to decrease GHG emissions, it was possible to unveil how the prevailing co-benefits rationale deterred the supposed original aim (CCM). Moreover, the analysis also showed how co-benefits themselves and their reasoning may not serve the prime objective of avoiding GHG and may even create more inequality.

As argued here, a co-benefits rationale is used to sustain and promote positive attitudes towards the CCM effort, but this practice can compromise the prime objective without adequate moral framing. Co-benefits literature and policy documents, as revealed here by our two examples, contain several reasons and arguments based on both deontological and utilitarian ethical traditions. However, neither of these ethical theories is able to properly justify them, due to the very dissimilar nature of the co-benefits and their practical settings.

The notions of well-being and freedom, as conceived by CA, offer a coherent line for the moral evaluation of these emergent outcomes, and also of the actions that originate them. By centring the moral argumentation and validation on enabling and favouring individual capacities and functionings, there is a chance of establishing a more coherent rationale.

The other pillar for an articulate moral justification of co-benefits is individual freedom. This freedom is defined as the factual possibility of choosing, individually and collectively, which benefits are morally valid and the reasons for that choice. Individual moral reflection, together with a system of social moral evaluation, creates a shared understanding of what is morally positive about both co-benefits and CCM strategies.

In a scenario where CA would shape a co-benefits rationale, the application of CCM strategies would rely mainly on bottom-up planning, which would increase citizen engagement in setting and meeting the targets for CCM.

Co-benefits and their rationale can become better allies of CCM action if they are grounded in a moral frame that integrates change and diversity. The effects of CCM actions are so multifaceted and complex that they pose severe implementation obstacles. We argue here that giving moral strength to emergent CCM outcomes that enable freedom and well-being can reduce these barriers.

\section{Acknowledgments}

We are indebted to anonymous reviewers for their valuable comments and suggestions. 


\section{Notes}

${ }^{1} \mathrm{NICHES}^{+}$is an example of an international project designed to decrease urban GHG. For further information visit the webpage http://www.transportresearch.info/web/projects/project_details.cfm?id=11075

${ }^{2}$ The Ecodrive Programme is an initiative for Dutch cities. For further information visit the webpage http://www.hetnieuwerijden.nl/

${ }^{3}$ The city of Stockholm developed the Environmental Zone initiative for tackling urban GHG. For further information visit the webpage http://foretag.stockholm.se/Tillstand/Trafik/MIljozon1/

4 'We are talking about taking measures that will add years to our life and add life to our years'. Wilfried Karmaus in Lambrechts (2001).

5 'The Hasselt MOBILITY PLAN [...] has 11 main objectives [...]: 1. Increase traffic safety; 2. Directional parking policy; 3 . Increase the use of bikes and public transport as traffic-safe alternatives to cars; 4 . Guarantee a right to mobility for everyone; 5 . Reduce the amount of space for private traffic and replace this with quality living space; 6 . Make the city more concentrated around public transport connections; 7. Improve accessibility for all forms of transport to the city from borough centres; 8 . Improve day-to-day facilities in the boroughs; 9 . Improve facilities for pedestrians in the boroughs; 10 . Manage the $\mathrm{CO}$ emissions by investing in methods to slow down the increasing number of kilometres travelled; 11 . Integrate the mobility goals into town planning (Lambrechts 2001: 6).

${ }^{6}$ Besides the establishment of a wide charging net, other incentives were also put in place for EV owners such as free charging in public charging stations, use of bus lanes, and toll exemptions for Oslo's ring road. Moreover, until the number of EV cars reaches 50.000, these vehicles are exempted from purchase tax and VAT (Pas 2014).

7 The works of Jack and Kinney (2010), Nemet and others (2010); (Zhang \& Wang 2011) are good examples of the positive weight that co-benefits and their rationale carry in literature.

${ }^{8}$ Mobility is here framed in the sense of possibility to leave and return to one's native country, which is established in the Universal Declaration of Human Rights in article 13-2.

${ }^{9}$ Deontology is considered here to integrate all moral theories that establish and reflect upon what is right to do in the tradition of Kantian ethics.

${ }^{10}$ The establishment of a right to an extended mobility [for example to migration] requires argumentation outside the Human rights moral and ethical framework (Pécoud \& De Guchteneire 2006).

11 'One striking outcome of the introduction of free public transport in Hasselt was that the number of visits to patients in the hospitals was reported to increase enormously. Free public transport might in this way be a means to prevent elderly people of becoming lonely' (Van Goeverden and others 2006: 7)

${ }^{12}$ For more on the concept of interest, read Scanlon (2008).

13 'Functionings represent parts of the state of a person - in particular the various things that he or she manages to do or be in leading a life. [...] [This] approach is based on a view of living as a combination of various 'doings and beings', with quality of life to be assessed in terms of the capability to achieve valuable functionings' (Sen 1993: 271). 
14 'The capability of a person reflects the alternative combinations of functionings the person can achieve, and from which he or she can choose one collection' (Sen 1993).

15 This topic is extensively discussed by Ahlroth (2014).

${ }^{16}$ Both Norway and Belgium have signed several international protocols regarding climate change, such as the Kyoto protocol (EEA 2014).

\section{References}

Ahlroth, S. (2014). The use of valuation and weighting sets in environmental impact assessment. Resources, Conservation and Recycling 85: 34-41. http://dx.doi.org/10.1016/j.resconrec.2013.11.012

Alkire, S. (2005). Why the capability approach?. Journal of human development 6(1): 115-135. http://dx.doi.org/10.1080/146498805200034275

Anand, P., Hunter, G., \& Smith, R. (2005). Capabilities and well-being: evidence based on the Sen-Nussbaum approach to welfare. Social Indicators Research 74(1): 9-55. http://dx.doi.org/10.1007/s11205-005-6518-z

Ang, G. a. V. M. (2013). Mobilising Private Investment in Sustainable Transport. The case of land-based passenger transport infrastructure. OECD Environment Working Papers, No. 56. Paris, OECD Publishing.

Aunan, K., Fang, J., Vennemo, H., Oye, K., \& Seip, H. M. (2004). Co-benefits of climate policy-lessons learned from a study in Shanxi, China. Energy Policy 32(4): 567-581. http://dx.doi.org/10.1016/S0301-4215(03)00156-3

Aunan, K., Mestl, H. E., Seip, H. M., Fang, J., D. O'Connor, D. O. C., Vennemo, H., \& Zhai, F. (2003). Co-benefits of CO2-reducing policies in China-a matter of scale? International Journal of Global Environmental Issues 3(3): 287-304. http://dx.doi.org/10.1504/IJGENVI.2003.003932

Ballet, J., Bazin, D., Dubois, J.-L., \& Mahieu, F.-R. (2011). A note on sustainability economics and the capability approach. Ecological Economics 70(11): 18311834. http://dx.doi.org/10.1016/j.ecolecon.2011.05.009

Basu, K. (1987). Achievements, capabilities and the concept of well-being. Social Choice and Welfare, 4(1), 69-76. http://dx.doi.org/10.1007/BF00433957

Biesbroek, G. R., Swart, R. J., Carter, T. R., Cowan, C., Henrichs, T., Mela, H., Rey, D. (2010). Europe adapts to climate change: Comparing National Adaptation Strategies. Global Environmental Change 20(3): 440-450. http://dx.doi.org/10.1016/j.gloenvcha.2010.03.005

Birkmann, J., Garschagen, M., Kraas, F., \& Quang, N. (2010). Adaptive urban governance: new challenges for the second generation of urban adaptation strategies to climate change. Sustainability Science 5(2): 185-206. http://dx.doi.org/10.1007/s11625-010-0111-3

Bollen, J., Brink, C. J., Eerens, H. C., \& Manders, A. J. G. (2009). Co-Benefits of Climate Change Mitigation Policies. http://dx.doi.org/10.1787/224388684356.

Boyle, A. (2006). Human Rights or Environmental Rights-A Reassessment. Fordham Environmental Law Review 18: 471.

Brand, R. (2008). Co-evolution of technical and social change in action: Hasselt's approach to urban mobility. Built Environment (1978-) 34(2): 182-199. 
C40Cities. (2012). Why Cities? Ending climate change begins in the city. Retrieved August 05, 2014, from http://www.c40.org/ending-climate-change-begins-inthe-city

C40Cities. (2015a). History of C40. Retrieved August 05, 2014, from http://www.c40.org/history

C40Cities. (2015b). Powering climate action: Cities as Global Change Makers. Retrieved August 06, 2014, from http://issuu.com/c40cities/docs/powering_climate_action_full_report

Canters, R. (2014). Hasselt cancels free public transport after 16 years (Belgium). Retrieved July 15, 2014, from http://www.eltis.org/discover/news/hasseltcancels-free-public-transport-after-16-years-belgium-0

CCAC. (2015). Climate \& Clean Air Coalition: Publications. Retrieved August 13, 2014, from http://www.unep.org/ccac/Publications/Publications/tabid/ 130293/Default.aspx

CELDF. (n.d.). Mission Statement. About us. Retrieved August 13, 2014, from http://www.celdf.org/mission-statement

Changhong, C., Bingyan, W., Qingyan, F., Green, C., \& Streets, D. G. (2006). Reductions in emissions of local air pollutants and co-benefits of Chinese energy policy: a Shanghai case study. Energy Policy 34(6): 754-762. http://dx.doi.org/10.1016/j.enpol.2004.07.007

Christ, R. (2014). ADP Technical Expert Meeting: Urban Environment Statement by Renate Christ Secretary of the Intergovernmental Panel on Climate Change. Bonn 10 June 2014. Retrieved August 05, 2014, from https://www.ipcc.ch/pdf/unfccc/sbsta40/140610_urban_environment_Christ. pdf

Combes, P.-P., Duranton, G., Gobillon, L., Puga, D., \& Roux, S. (2012). The Productivity Advantages of Large Cities: Distinguishing Agglomeration From Firm Selection. Econometrica 80(6): 2543-2594. http://dx.doi.org/10.3982/ ECTA8442

Corfee-Morlot, J., Kamal-Chaoui, L., Donovan, M. G., Cochran, I., Robert, A., \& Teasdale, P.-J. (2009). Cities, Climate Change and Multilevel Governance. Retrieved September 12, 2014, from http://www.oecd.org/governance/ regional-policy/44232263.pdf

Cresswell, T. (2006). The Right to Mobility: The Production of Mobility in the Courtroom. Antipode 38(4): 735-754. http://dx.doi.org/10.1111/j.14678330.2006.00474.x

Creutzig, F., \& He, D. (2009). Climate change mitigation and co-benefits of feasible transport demand policies in Beijing. Transportation Research Part D: Transport and Environment 14(2): 120-131. http://dx.doi.org/10.1016/j.trd.2008.11.007

Crisp, R. (2013). The Oxford handbook of the history of ethics. Oxford, Oxford University Press. http://dx.doi.org/10.1093/oxfordhb/9780199545971.001.0001

Dave, P. (2014). Bangalore: India's Only Metro City with 'Profit Making' Bus System. Retrieved November 10, 2015, from http://www.sustainablecitiescollective.com/pratik-dave/244831/bangaloreexclusive-metro-india-having-profit-making-public-transport-system

de Sousa Santos, B. (1999). Towards a multicultural conception of human rights. Spaces of Culture: City-Nation-World 214-222. 
De Witte, A., Macharis, C., Lannoy, P., Polain, C., Steenberghen, T., \& Van de Walle, S. (2006). The impact of "free" public transport: The case of Brussels. Transportation Research Part A: Policy and Practice 40(8): 671-689. http://dx.doi.org/10.1016/j.tra.2005.12.008

Deneulin, S., \& McGregor, J. A. (2010). The capability approach and the politics of a social conception of wellbeing. European Journal of Social Theory 13(4): 501519. http://dx.doi.org/10.1177/1368431010382762

Díaz, R., \& Paez, F. (n.d.). Guaranteeing the "right to mobility" in Mexico City. Retrieved August 12, 2014, from http://www.wricities.org/our-work/projectcity/guaranteeing-right-mobility-mexico-city

Dietz, S., \& Asheim, G. B. (2012). Climate policy under sustainable discounted utilitarianism. Journal of Environmental Economics and Management 63(3): 321-335. http://dx.doi.org/10.1016/j.jeem.2012.01.003

EEA. (2014) Total greenhouse gas (GHG) emission trends and projections. Retrieved August 03, 2014, from http://www.eea.europa.eu/data-andmaps/indicators/greenhouse-gas-emission-trends-5/assessment-1

Eltis. $(2008,2014)$. Electronic vehicles for companies in Stavanger, Norway. Retrieved August 08, 2014, from http://www.eltis.org/discover/casestudies/electronic-vehicles-companies-stavanger-norway

EVNorway. (2012). EV Norway. Powered by Nature: A guide to Norway, the world's leading EV market. Retrieved August 08, 2014, from http://www.evnorway.no/\#/now

Feinberg, J. (1967). The forms and limits of utilitarianism. The Philosophical Review 76(3): 368-381. http://dx.doi.org/10.2307/2183625

Flyvbjerg, B., Skamris Holm, M. K., \& Buhl, S. L. (2005). How (in) accurate are demand forecasts in public works projects?: The case of transportation. Journal of the American Planning Association 71(2): 131-146. http://dx.doi.org/10.1080/01944360508976688

Follett, R. F., \& Reed, D. A. (2010). Soil carbon sequestration in grazing lands: societal benefits and policy implications. Rangeland Ecology \& Management 63(1): 4-15. http://dx.doi.org/10.2111/08-225.1

Galey, D. (2014). License to Ride: Free Public Transportation for Residents of Tallinn. Critical Planning, 21(1). Retrieved August 04, 2014, from http://www.escholarship.org/uc/item/4p98p21x

Ganten, D., Haines, A., \& Souhami, R. (2010). Health co-benefits of policies to tackle climate change. The Lancet 376(9755): 1802-1804. http://dx.doi.org/10.1016/S0140-6736(10)62139-3

Gleick, P. H. (1998). The human right to water. Water policy 1(5): 487-503. http://dx.doi.org/10.1016/S1366-7017(99)00008-2

Haldén, P. (2007). The geopolitics of climate change. Challenges to the International System. Stockholm: FOI.

Hannisdahl, O. H., Malvik, H. V., \& Wensaas, G. B. (2013). The future is electric! The EV revolution in Norway -Explanations and lessons learned. Paper presented at the Electric Vehicle Symposium and Exhibition (EVS27), 2013 World. http://dx.doi.org/10.1109/EVS.2013.6914921

Harlan, S. L., \& Ruddell, D. M. (2011). Climate change and health in cities: impacts of heat and air pollution and potential co-benefits from mitigation and 
adaptation. Current Opinion in Environmental Sustainability 3(3): 126-134. http://dx.doi.org/10.1016/j.cosust.2011.01.001

Hawkins, T. R., Singh, B., Majeau-Bettez, G., \& Stromman, A. H. (2013).

Comparative Environmental Life Cycle Assessment of Conventional and Electric Vehicles. Journal of Industrial Ecology 17(1): 53-64.

http://dx.doi.org/10.1111/j.1530-9290.2012.00532.x

Herring, H., Sorrell, S., \& Elliott, D. (2009). Energy efficiency and sustainable consumption: the rebound effect: Palgrave Macmillan Basingstoke.

Holtsmark, B. (2012). Elbilpolitikken-virker den etter hensikten? Retrieved November 15, 2015, from

http://brage.bibsys.no/xmlui/bitstream/handle/11250/178116/HoltsmarkElbil 2012.pdf? sequence $=1$ \&isAllowed $=y$

Hooker, B. (2015) Rule Consequentialism. The Stanford Encyclopedia of Philosophy. Edward N. Zalta (ed.). Retrieved July 13, 2014, Retrieved from http://plato.stanford.edu/archives/win2015/entries/consequentialism-rule/

IOM, \& UNDESA. (2012). UN System task Team on the Post-2015 UN Development Agenda. Retrieved September 17, 2014, from http://www.un.org/millenniumgoals/pdf/Think\%20Pieces/13_migration.pdf

IPCC (2007a). Climate change 2007: Mitigation of climate change: contribution of Working Group III to the Fourth assessment report of the Intergovernmental Panel on Climate Change. Working Group III., [Core Writing Team Metz, B., Meyer, L., Bosch, P. R., Dave, R., \& Davidson, O. R. (eds.)]. Cambridge, New York, Cambridge University Press.

IPCC. (2007b). Climate Change 2007: Synthesis Report. Contribution of Working Groups I, II and III to the Fourth Assessment Report of the Intergovernmental Panel on Climate Change. [Core Writing Team, Pachauri, R.K \& Reisinger, A. (eds.)]. IPCC, Geneva, Switzerland.

IPCC. (2013). Summary for Policymakers. In: Climate Change 2013: The Physical Science Basis. Contribution of Working Group I to the Fifth Assessment Report of the Intergovernmental Panel on Climate Change. Cambridge, New York, Cambridge University Press.

Jack, D. W., \& Kinney, P. L. (2010). Health co-benefits of climate mitigation in urban areas. Current Opinion in Environmental Sustainability, 2(3): 172-177. http://dx.doi.org/10.1016/j.cosust.2010.06.007

Jackson, R. B., Jobbágy, E. G., Avissar, R., Roy, S. B., Barrett, D. J., Cook, C. W., \& Murray, B. C. (2005). Trading water for carbon with biological carbon sequestration. Science 310(5756): 1944-1947.

http://dx.doi.org/10.1126/science.1119282

Jakob, M. (2006). Marginal costs and co-benefits of energy efficiency investments The case of the Swiss residential sector. Energy Policy 34(2): 172-187. http://dx.doi.org/10.1016/j.enpol.2004.08.039

Jamieson, D. (2013). Climate change, consequentialism, and the road ahead. The Chicago Journal of International 13(2): 439-468.

Jamieson, D. (2007). When utilitarians should be virtue theorists. Utilitas 19(02): 160-183. http://dx.doi.org/10.1017/S0953820807002452

Jamieson, D. (2001). Climate change and global environmental justice. Changing the atmosphere: Expert knowledge and global environmental governance 287-307. 
Jiang, P., Chen, Y., Geng, Y., Dong, W., Xue, B., Xu, B., \& Li, W. (2013). Analysis of the co-benefits of climate change mitigation and air pollution reduction in China. Journal of Cleaner Production 58: 130-137. http://dx.doi.org/10.1016/j.jclepro.2013.07.042

Jochem, E., \& Madlener, R. (2003, December). The forgotten benefits of climate change mitigation: Innovation, technological leapfrogging, employment, and sustainable development. In Workshop on the Benefits of Climate Policy: Improving Information for Policy Makers.

Kalkstein, L. S. (1993). Direct impacts in cities. The Lancet 342(8884): 1397-1399. http://dx.doi.org/10.1016/0140-6736(93)92757-K

Krugman, P. (1993). On the number and location of cities. European Economic Review 37(2): 293-298. doi:http://dx.doi.org/10.1016/0014-2921(93)90017-5

Lambrechts, D. (2001). Hasselt Samen Anders Mobiel-The story behind the sustainable mobility policy for Hasselt in the beginning of the 21st century. Retrieved August 08, 2014, from http://sigfus.blog.is/users/02/sigfus/files/hasselt_belgium_english_01.pdf

Mabsout, R. (2015). Mindful capability. Ecological Economics, 112, 86-97. http://dx.doi.org/10.1016/j.ecolecon.2015.01.008

McEvoy, D., Lindley, S., \& Handley, J. (2006). Adaptation and mitigation in urban areas: synergies and conflicts. Proceedings of the ICE-Municipal Engineer 159(4): 185-191. http://dx.doi.org/10.1680/muen.2006.159.4.185

McKibbin, W. J., \& Wilcoxen, P. J. (2002). The Role of Economics in Climate Change Policy. The Journal of Economic Perspectives 16(2): 107-129. http://dx.doi.org/10.2307/2696499

Moss, R. H., Edmonds, J. A., Hibbard, K. A., Manning, M. R., Rose, S. K., van Vuuren, D. P., Wilbanks, T. J. (2010). The next generation of scenarios for climate change research and assessment. Nature 463(7282) : 747-756. doi:http://www.nature.com/nature/journal/v463/n7282/suppinfo/nature0882 3_S1.html. http://dx.doi.org/10.1038/nature08823

Nemet, G., Holloway, T., \& Meier, P. (2010). Implications of incorporating airquality co-benefits into climate change policymaking. Environmental Research Letters 5(1): 014007. http://dx.doi.org/10.1088/1748-9326/5/1/014007

O'Brien, K., Clair, A. L. S., \& Kristoffersen, B. (Eds.). (2010). Climate change, ethics and human security. Cambridge, New York, Cambridge University Press. http://dx.doi.org/10.1017/cbo9780511762475

OECD. (2014). Benefits of Climate Change Policies. Retrieved August 11, 2014, from http://www.oecd.org/fr/env/cc/benefitsofclimatechangepolicies.htm

OHCHR, UNHabitat, \& WHO. (2010). The Right to Water:Fact Sheet No. 35. Retrieved October 18, 2014, from http://www.ohchr.org/Documents/Publications/FactSheet35en.pdf

Olander, L. P., Galik, C. S., \& Kissinger, G. A. (2012). Operationalizing REDD+: scope of reduced emissions from deforestation and forest degradation. Current Opinion in Environmental Sustainability 4(6): 661-669. http://dx.doi.org/10.1016/j.cosust.2012.07.003

Onaindia, M., de Manuel, B. F., Madariaga, I., \& Rodríguez-Loinaz, G. (2013). Cobenefits and trade-offs between biodiversity, carbon storage and water flow regulation. Forest Ecology and Management 289: 1-9.

http://dx.doi.org/10.1016/j.foreco.2012.10.010 
Osmani, S. R. (2008). The Sen system of social evaluation. In K. Basu \& R. Kanbur (Eds.), Arguments for a Better World: Essays in Honor of Amartya Sen: Volume I: Ethics, Welfare, and Measurement: Volume I: Ethics, Welfare, and Measurement. Oxford, New York: Oxford University Press. http://dx.doi.org/10.1093/acprof:oso/9780199239115.003.0003

Pas, J.-W. V. D. (2014). Oslo: electric vehicle capital of the world (Norway). Retrieved August 08, 2014, from http://www.eltis.org/discover/casestudies/oslo-electric-vehicle-capital-world-norway

Pécoud, A., \& De Guchteneire, P. (2006). International migration, border controls and human rights: Assessing the relevance of a right to mobility. Journal of Borderlands Studies 21(1): 69-86. http://dx.doi.org/10.1080/08865655.2006.9695652

Pew Center. (2009). Climate Change Mitigation measures in European Union. Retrieved August 23, 2014, from http://www.c2es.org/docUploads/eu-factsheet-12-05-09.pdf

Puppim de Oliveira, J. A. (2013). Learning how to align climate, environmental and development objectives in cities: lessons from the implementation of climate co-benefits initiatives in urban Asia. Journal of Cleaner Production 58: 7-14. http://dx.doi.org/10.1016/j.jclepro.2013.08.009

Rea, B. R. (1986). The interplay of legal and moral rights. The Journal of Value Inquiry: 20(3): 235-239. http://dx.doi.org/10.1007/BF00148302

Ringel, M. (2006). Fostering the use of renewable energies in the European Union: the race between feed-in tariffs and green certificates. Renewable Energy 31(1): 1-17. http://dx.doi.org/10.1016/j.renene.2005.03.015

Rübbelke, D. T. G. (2011). International support of climate change policies in developing countries: Strategic, moral and fairness aspects. Ecological Economics 70(8): 1470-1480. http://dx.doi.org/10.1016/j.ecolecon.2011.03.007

Røsland, S. B. (2013). Urban ecology in Oslo. Retrieved August 04, 2014, from http://www.climateactionprogramme.org/climate-leaderpapers/urban_ecology_in_oslo

Sagoff, M. (1986). Values and preferences. Ethics 96(2): 301-316.

Salman, S., \& McInerney-Lankford, S. (2004). The human right to water: Legal and policy dimensions. Washington, World Bank.

Scanlon, T. M. (2008). Rights and interests. In K. Basu \& R. Kanbur (Eds.), Arguments for a Better World: Essays in Honor of Amartya Sen: Volume I: Ethics, Welfare, and Measurement: Volume I: Ethics, Welfare, and Measurement. Oxford, New York, Oxford University Press.

Seghezzo, L. (2009). The five dimensions of sustainability. Environmental Politics 18(4): 539-556. http://dx.doi.org/10.1080/09644010903063669

Selvakkumaran, S., \& Limmeechokchai, B. (2013) Energy security and co-benefits of energy efficiency improvement in three Asian countries. Renewable and Sustainable Energy Reviews 20: 491-503.

Sen, A. (1985). Well-being, agency and freedom: the Dewey lectures 1984. The Journal of Philosophy 169-221.

Sen, A. (1993). Capability and well-being. Retrieved December 03, 2014, from http://digamo.free.fr/hausman8.pdf\#page $=276$ 
Shrestha, R. M., \& Pradhan, S. (2010). Co-benefits of CO2 emission reduction in a developing country. Energy Policy 38(5): 2586-2597.

http://dx.doi.org/10.1016/j.enpol.2010.01.003

Shukla, P. R. (1999). Justice, equity and efficiency in climate change: a developing country perspective. Fair weather 145-159.

Singh, B., Stromman, A. H., \& Hertwich, E. G. (2012). Scenarios for the environmental impact of fossil fuel power: Co-benefits and trade-offs of carbon capture and storage. Energy 45(1) 762-770. http://dx.doi.org/10.1016/j.energy.2012.07.014

Smith, A. (2013). The Climate Bonus: Co-benefits of Climate Policy. London \& New York, Earthscan/Routledge.

Smith, K. R., \& Haigler, E. (2008). Co-benefits of climate mitigation and health protection in energy systems: scoping methods. Annual Review of Public Health 29: 11-25.

Speck, S. (1999). Energy and carbon taxes and their distributional implications. Energy Policy 27(11): 659-667. http://dx.doi.org/10.1016/S03014215(99)00059-2

Tanner, T., Mitchell, T., Polack, E., \& Guenther, B. (2009). Urban governance for adaptation: assessing climate change resilience in ten Asian cities. IDS Working Papers 2009(315): 01-47.

Teng, F., \& Jotzo, F. (2014). Reaping the Economic Benefits of Decarbonization for China. China \& World Economy 22(5): 37-54.

UN. (2014). World Urbanization Prospects-The 2014 Revision. New York, United Nations Publications.

UNHabitat. (2012). Climate Change. Retrieved September, 25, 2014 from http://unhabitat.org/urban-themes/climate-change/

Van Audenhove, F.-J., Korniichuk, O., Dauby, L., \& Pourbaix, J. (2014). The Future of Urban Mobility 2.0: Imperatives to Shape Extended Mobility Ecosystems of Tomorrow. Retrieved August, 27, 2014 from http://www.adlittle.com/downloads/tx_adlreports/2014_ADL_UITP_Future_ of_Urban_Mobility_2_0_Full_study.pdf

Van Goeverden, C., Rietveld, P., Koelemeijer, J., \& Peeters, P. (2006). Subsidies in public transport. European Transport $\backslash$ Trasporti Europei 32: 5-25

Van Neste, S. L., \& Sénécal, G. (2015). Claiming Rights To Mobility Through The Right To Inhabitance: Discursive Articulations from Civic Actors in Montreal. International Journal of Urban and Regional Research 39(2): 218-233. http://dx.doi.org/10.1111/1468-2427.12215

Vasconcellos Oliveira, R., Thorseth, M., \& Brattebø, H. (2016). The Potential OfCoBenefits In Climate Change Mitigation Strategy: A Case For An Inclusive Moral Justification. Manuscript in preparation.

Vuchic, V. R. (1999). Transportation for livable cities. New Brunswick: Rutgers Center for Urban Policy Research.

West, J. J., Smith, S. J., Silva, R. A., Naik, V., Zhang, Y., Adelman, Z., Lamarque, J.-F. (2013). Co-benefits of mitigating global greenhouse gas emissions for future air quality and human health. Nature Clim. Change, 3(10), 885-889. http://dx.doi.org/10.1038/nclimate2009.

WHO. (2012). Health in the green economy: health co-benefits of climate change mitigation-transport sector: World Health Organization. 
WHO, W. H. O. (2010). Part one. The dawn of an urban world. In W. H. O. WHO (Ed.), Hidden Cities: Unmasking And Overcoming Health Inequities In Urban Settings: WHO, World Health Organization.

Wilkinson, R. G., Pickett, K. E., \& De Vogli, R. (2010). Equality, sustainability, and quality of life. British Journal of Medicine, 341.

Wittman, H. K., \& Caron, C. (2009). Carbon Offsets and Inequality: Social Costs and Co-Benefits in Guatemala and Sri Lanka. Society \& Natural Resources, 22(8), 710-726. http://dx.doi.org/10.1080/08941920802046858

Yi, H. (2013). Clean energy policies and green jobs: An evaluation of green jobs in US metropolitan areas. Energy Policy, 56, 644-652.

Ürge-Vorsatz, D., Novikova, A., \& Sharmina, M. (2009). Counting good: quantifying the co-benefits of improved efficiency in buildings. Paper presented at the European Council for an Energy Efficient Economy.

Zhang, J., \& Wang, C. (2011). Co-benefits and additionality of the clean development mechanism: An empirical analysis. Journal of Environmental Economics and Management, 62(2), 140-154. 